\title{
Los derechos humanos y su puesta en marcha por actores globales
}

\section{Human rights and their implementation by global actors}

\section{Concepción Delgado Parra (D)}

Universidad Autónoma de la Ciudad de México

concepcion.delgado@uacm.edu.mx

\section{Resumen}

Discutir el modo en que los derechos humanos son puestos en marcha por actores globales que son capaces de hacerlos explícitos y realizables en el marco de un horizonte simbólico, donde el derecho a tener derechos y el derecho a cuestionar el derecho abre la posibilidad de llevar a cabo un ejercicio de acción política dirigida a actualizarlos. Dos cuestiones serán discutidas en este sentido: el universalismo interactivo de Seyla Benhabib y el papel de la acción politica de actores globales llevada a cabo mediante iteraciones democráticas desarrolladas por diversos activistas que producen una re-articulación entre la política y la ley, colocando los derechos humanos en el registro arendtiano del "derecho a tener derechos", a la vez que visibiliza una crítica radical a la idea universal de los derechos humanos que los vuelven irrealizables en el mundo presente.

Palabras clave: Derechos humanos, universalismo interactivo, actores globales, iteraciones democráticas, acción politica.

\begin{abstract}
Discussing the way human rights are implemented by global actors who are able to make them explicit and achievable within the framework of a symbolic horizon where the right to have rights and the right to question the law exist opens up the possibility of undertaking an exercise of political action designed to update them. Two issues will be discussed in this respect: the interactive universalism of Seyla Benhabib and the role of the political action of global actors, developed through democratic iterations that re-establish the link between politics and law, placing human rights within the Arendtian register of the "right to have rights", while providing a radical critique of the universal idea of human rights that makes them impossible to achieve in today's world.
\end{abstract}

Keywords: Human rights, interactive universalism, global actors, democratic iterations, political action.

Articulo: Recibido 17 de mayo de 2019 y aprobado el 6 de octubre de 2019.

\section{Cómo citar este artículo:}

Delgado Parra, C. (2019). Los derechos humanos y su puesta en marcha por actores globales. Reflexión Politica, 21(43), 63-76. doi: 10.29375/01240781.3615 


\section{Introducción}

La democracia moderna exige nuevas formas de configuración de los derechos humanos. Coloca a las personas frente a la exigencia de hacerlos explícitos y realizables en el marco de un horizonte simbólico donde el derecho a tener derechos y el derecho a cuestionar el derecho arroja permanentemente a un ejercicio de acción política dirigida a actualizarlos, cada vez más. Pero ¿cómo crear un espacio público de discusión y debate sobre el fundamento y alcance entre la justicia y la realización de los derechos humanos? Este texto propone discutir el principio de acción política leído en clave de iteraciones democráticas, entendidas como procesos complejos de argumentación, deliberación e intercambio público a través de los cuales se cuestionan y contextualizan reivindicaciones de principios universalistas, se trata de repeticiones-en-transformaciones lingüísticas, legales, culturales y políticas, invocaciones que también son revocaciones dirigidas a transformar el sentido original que les dio origen (Benhabib, 2004), lo que se apertura es un horizonte interpretativo global que permite a los participantes abrir un camino para cuestionar la idea universal de los derechos humanos y, al mismo tiempo, ampliar el campo de su realización concreta. Se parte del supuesto de que la fuente de estos grupos y su fuerza para incidir en la agenda pública, nacional e internacional, está directamente relacionada con su capacidad para llevar a cabo una acción política colectiva, derivada de necesidades y un impulso de solidaridad generado por la potencia de una utopía social que asume este trabajo de acción política colectiva a partir de un presentimiento de esperanza, cuya práctica no remite a la inactividad de no hacer nada en el presente, sino a la actividad de anticipar-haciendo y, de esta manera, trascender "lo dado en el momento". Lo que sigue de esto es una nueva apreciación de la articulación entre justicia y derechos humanos. Dos cuestiones serán discutidas en este sentido, el universalismo interactivo de Seyla Benhabib, que empuja hacia la creación de un espacio de diálogo entre la norma y la utopía social, encaminado a potenciar el "derecho a tener derechos", desde una perspectiva que reconoce la existencia del "otro generalizado", atisbado en las comunidades de legalidad y justicia, y del "otro concreto", expresado en las comunidades de necesidad y solidaridad, cuya expresión se acuerpa en el desarrollo de los movimientos sociales contemporáneos dirigidos a la defensa y realización de los derechos humanos, en un marco global de normas cosmopolitas. De acuerdo con lo anterior, se propone una reflexión en torno al papel que la acción política global, puesta en marcha mediante iteraciones democráticas desarrolladas por diversos activistas, produce en términos de la rearticulación que logran establecer entre la política y la ley, lo que les permite colocar los derechos humanos en el registro arendtiano del "derecho a tener derechos", a la vez que realizan una crítica radical a la idea universal de los derechos humanos que los vuelven irrealizables en el mundo presente.

En este contexto se desarrolla el contenido de este trabajo: 1. Los derechos humanos desde la perspectiva universalista interactiva de Seyla Benhabib. Lo que aquí se postula es mostrar que lo singular, el "otro concreto" -un "yo" encarnado e incrustado en las relaciones humanas, cuya identidad se constituye narrativamente, y en la reformulación del punto de vista moral como la realización contingente de una forma interactiva de racionalidad expresada en el respeto a la dignidad de la persona- se articula con el "otro generalizado" -referido al punto de vista que exige reconocer a cada individuo como ser racional sujeto a derechos y deberes del mismo modo que quisiéramos vernos a nosotros mismos-. Ambas posturas interactúan en un procedimiento que pone en relación norma y solidaridad, derecho y amistad, historicidad y vida cotidiana, dando lugar a un proceso de interacción en el que lo particular y lo universal dialogan sobre la forma en que los derechos humanos tendrian que reconciliarse, tanto en el terreno normativo como en la experiencia cotidiana de las personas en el marco de una democracia deliberativa. La reformulación del universalismo benhabibiano surge, precisamente, en el intersticio en el que se manifiesta la ceguera de la teoría moral que ignora las transformaciones de la esfera privada y las repercusiones que esta introduce a la esfera pública. En esto radica la importancia de presentar los argumentos sobre el universalismo interactivo. Al poner en relación lo concreto con lo generalizado se apertura la posibilidad de visibilizar un camino en el que los derechos humanos se vinculan a la persona 
concreta, al mismo tiempo que remiten a derechos universales de los que nadie puede ser excluido. Esta lectura propuesta por Benhabib se acuerpa en lo que Arendt denominó "el derecho a tener derechos".

2. Los derechos humanos puestos en marcha por el activismo contemporáneo. En este apartado se abordan experiencias en las que es posible identificar el modo en que diferentes grupos (migrantes, indígenas, mujeres, población LGBTTTI, entre otros), apelando a su capacidad para actuar políticamente "juntos", exigen el respeto a los derechos humanos mediante una puesta en escena de sus demandas y exigencia de justicia en el espacio público, de manera "reiterada" -para explicar este proceso nos referiremos a la noción de "iteración democrática”, desarrollada por Benhabiby apelando a normas cosmopolitas, derivadas de la Declaración Universal de los Derechos Humanos, sobre las que sostienen sus reclamos, amplían los marcos de negociación dirigidos a la búsqueda de la justicia global y local, impactando de manera creciente en la extensión del régimen de derechos humanos que, pese a todas sus hipocresías a escala mundial, da lugar a nuevas formas de realización. Las luchas que se llevan a cabo contra la injusticia se dirigen, ante todo, contra la arbitrariedad del poder, esta es la importancia de introducir la acción política como punto de ruptura para la exigencia de los grupos excluidos, de quienes han sido víctimas en este proceso. En este sentido, el impulso latente que se opone a la injusticia no se reduce a querer algo, o más de algo, sino a la resistencia de ser dominado, acosado y rechazado por más tiempo en el reclamo de los derechos humanos de una persona. Este reclamo implica la exigencia de que no existen relaciones políticas ni sociales que no puedan justificarse adecuadamente ante los involucrados. En esto reside la profunda esencia de la justicia, cuestión que pone en marcha el activismo contemporáneo. No se trata de una definición que resuelva "quién determina, quién recibe qué”, sino que una demanda de justicia siempre es emancipatoria; hablando de manera reflexiva, diremos que se basa en el reclamo de ser respetado como un ser sujeto de justificación, ser respetado en la dignidad de uno mismo como alguien que puede proporcionar y exigir justificaciones sobre el trato que da y recibe, en lo singular y en lo plural.

3. Transfiguración de los derechos humanos en el marco del "otro generalizado" y el "otro concreto". Por último, discutiremos el modo en que los activistas globales demandan la exigencia de justicia y realización de los derechos humanos, mediante el ejercicio de iteraciones democráticas, colocando en el centro del debate la importancia de la distinción entre la legalidad y los derechos, y una ética del cuidado y la responsabilidad. Así como su capacidad para visibilizar el modo en que la postura racionalista anula al otro concreto, la manera en que se impone la singularidad de la conciencia "de los iguales" que pretende ser inmediatamente universal. El resultado es la construcción de una solidaridad en torno a la que se enlazan los activistas globales en su reclamo de justicia, donde se apuntalan otros modos de relación para comprender la moralidad; un proceso que podría llevarnos a establecer juicios morales justos que deriven en la realización de los derechos humanos evocados en el "derecho a tener derechos" propuesto por Arendt.

\section{Los derechos humanos desde la perspectiva universalista interactiva de seyla benhabib}

La razón de Occidente edificó un discurso dirigido a enfrentar la desigualdad y la injusticia producidas por el capitalismo global basado en un principio de justificación universal. Sin embargo, los efectos de las instituciones y prácticas heredadas no resisten el menor escrutinio, sus efectos no responden ni a la racionalidad, ni a la humanidad que pregonan. Frente a este contexto, el lenguaje de los derechos humanos emerge como uno de los discursos más utilizados en el escenario público, nacional e internacional, para discutir este dilema. No obstante, su amplitud, defensa e institucionalización, se convierten en un lenguaje no contestado. En este sentido, resulta urgente abordar la manera en que las reivindicaciones de universalidad podrían reconciliarse con las afirmaciones de particularidad. Encontrar un punto de cruce entre la unidad de la razón y la diversidad de las formas de vida, particularmente, en la realización de los derechos humanos. En este texto, siguiendo a Hannah Arendt y Seyla Benhabib, argumento que existe un derecho moral fundamental, el "derecho a tener derechos" de cada ser humano particular. Esto significa ser reconocido por otros y asumir que todas las personas somos titulares de respeto moral y legal en toda comunidad humana. Desde esta 
perspectiva, los derechos humanos encauzarían los principios morales que protegen la libertad de acción política, focalizada a impulsar la convergencia entre la especificación legal universal de los derechos y el reclamo particular justificado de los mismos. De lo anterior, se deriva, necesariamente, la conexión entre derechos humanos como principio moral y la manera en que éstos adquieren su forma jurídicolegal.

En la actualidad, existe un desacuerdo acerca de la justificación filosófica como contenido de los derechos humanos (Benhabib, 2011: 60). Hay quienes afirman que en los últimos años el compromiso filosófico disminuye en la medida en que el compromiso político crece (Buchanan, 2010). Michael Walzer (1994) argumenta que los derechos humanos constituyen el núcleo de la debilidad moral del universalismo contemporáneo; mientras que Martha Nussbaum considera que configuran el centro para discutir las condiciones razonables a partir de un consenso político mundial (Naussbaum, 2006: 281-91). Incluso, pensadores como John Rawls, reducen el concepto de derechos humanos a un nivel mínimo de instituciones políticas bien ordenadas para todos los pueblos (Rawls, 1999: 552). En esta reflexión, ensayaremos recuperar la comprensión de los derechos humanos a partir de la estrategia de Seyla Benhabib (2004) que propone ampliarla en términos del principio arendtiano del "derecho a tener derechos". Esto supone poner en juego, tanto el derecho político, identificado en Arendt como el principio político fundamental, vinculado estrechamente con el "derecho a la pertenencia a una comunidad política", como la exigencia de cada persona humana a ser reconocida y protegida como una personalidad jurídica por la comunidad mundial, postulada por Benhabib. Dicha estrategia requiere, necesariamente, discutir el modo en que el universalismo se pone en relación con lo particular. Para tomar un término de Benhabib, la forma que adquiere el universalismo interactivo en el que el "otro generalizado" y el "otro concreto" toman presencia en el ejercicio de los derechos humanos.

La obra de Seyla Benhabib constituye una de las reflexiones más sugerentes en el ámbito de la Teoría Crítica para abordar el dilema de los derechos humanos referido al diálogo entre lo universal y lo particular. En su trayecto intelectual reformula la cuestión del universalismo tradicional, que predica la democracia deliberativa propuesta por Habermas, cuyo desarrollo se expresa en la Teoría de la acción comunicativa (Habermas, 1987a, 1987b), hacia una lectura que la pensadora denomina universalismo interactivo. El punto de partida de su crítica se refiere tanto a la postura de la ética del discurso como a la deliberación ética, señalando que las teorías morales universalistas en la tradición occidental, sostenidas desde Hobbes hasta Rawls, son sustitutivistas. El universalismo que éstas defienden identifican experiencias de un grupo específico de sujetos y lo generalizan como caso paradigmático de lo humano como tal (Benhabib, 2006a: 176). La particularidad de la reflexión en Benhabib radica en evitar las oposiciones generales que derivan en la limitada elección de decidir entre un camino universal o uno particular; utiliza un procedimiento en el que discute los problemas generados en el contexto de la modernidad y somete al pensamiento ilustrado a un constante ejercicio de crítica, al mismo tiempo que lo sujeta a un proceso de aprendizaje en la experiencia presente (Benhabib, 1986: 1-6). Deliberadamente pone en relación el pasado con los turbulentos tiempos presentes.

En este primer apartado discutiremos la puesta en marcha del derecho a tener derechos y el derecho a cuestionar el derecho desde la comprensión del universalismo interactivo. Esta perspectiva nos permitirá identificar la tensión entre el discurso universalista de las promesas de justicia, igualdad, derechos civiles y publicidad, contenidas en las comunidades de legalidad y derechos, que encuentran su expresión en el "otro generalizado", y el lenguaje utópico de la amistad, solidaridad y felicidad, propio de la comunidad de necesidades y solidaridad, manifiesto en la figura del "otro concreto" y acuerpado en el principio de la singularidad. Se trata de vislumbrar las tensiones contenidas entre la norma y la utopía, expresadas en la paradoja de la ley de lo universal (justificación universalista de los derechos humanos) frente a la ley de lo singular (forma particular de demandar y poner en cuestión tales derechos, a partir de la libertad asumida como acción política colectiva) que anidan en el núcleo de los derechos humanos, cuya salida no radica en la elección entre la norma o la utopía, sino en la capacidad de mantenerlas en una relación tensional permanente a partir del ejercicio de la acción política global.

Benhabib (2006a) argumenta que la norma corresponde al espacio de la legalidad y del 
derecho. Por el contrario, la utopía está vinculada a una política de transfiguración, apela a la transformación radical de las figuras que toma la vida en común. En ese sentido, la utopía se adhiere a la realización de distintas formas de vida. Tiene elementos de concreción y realización humana: es lo utópico-concreto, lo anticipatorio (que no coincide en absoluto con la idea de la ensoñación utópica-abstracta a la que casi siempre ha sido encadenada la idea de la utopía). De ahí que la utopía, siguiendo a Ernst Bloch, sea la actividad de la inteligida, del presentimiento de la esperanza. Espera, que de ninguna manera, remite a la inactividad de no hacer nada en el presente, sino la actividad de anticipar-haciendo, lo que trasciende "lo dado en el momento" (Bloch, 1977: 147). Para Benhabib, la teoría habermasiana encuentra su límite en el modo como articula las promesas universalistas de justicia, igualdad, derechos civiles y publicidad, con el lenguaje utópico que supone la amistad, solidaridad y felicidad, al aparecer como dos cuestiones divididas (Benhabib, 2011). En ese trayecto, la interrogante que abre a la ética comunicativa es si el legado crítico utópicoemancipatorio está en condiciones de llevarse a cabo por la vía que Habermas postula. Cuestionamiento que rasga en dos direcciones que parecieran irreconciliables. Por una parte, genera un modelo de esfera pública legalista donde las cuestiones de justicia constituyen su objetivo principal frente a otras formas de relación tradicionalmente relegadas a la esfera privada, tales como la amistad, el amor, la solidaridad y las identidades, dejándolas fuera de la consideración legal e institucional (Benhabib, 1986: 310 ). Ante esta disyuntiva, en la que se contrapone el modelo jurídico o participativo inherente a la Teoría de la acción comunicativa, Benhabib entrevé como resultado la separación entre las cuestiones de justicia y la vida buena. Por ello, su crítica va dirigida a destacar que la participación -gestada en la comunidad de necesidades y solidaridad- precede a la universalización -configurada en la comunidad de legalidad y derecho-, ya que no existe justicia sin participación particular gestada en los procesos de amistad, solidaridad y felicidad (Benhabib, 2006a: 177-182).

Justicia y vida buena encuentran su punto de intersección, dirá Benhabib, en el momento en que seamos capaces de discutir la aporía del universalismotradicional. Con estepropósito, rastrea la crítica que realiza el comunitarismo, feminismo y posmodernismo. A pesar de las divergencias que existen entre estas tres perspectivas, se enfoca en la "sospecha" que comparten estos debates sobre la pretensión universalista y universalizadora de la modernidad. Los comunitaristas, como Alasdair MacIntyre, Michel Sandel, Charles Taylor y Michael Walzer, dudan de los presupuestos epistemológicos y de la visión normativa de las teorías políticas liberales; las teóricas del feminismo como Carol Gilligan, Carole Pateman, Susan Moller Okin, Virginia Held, Iris Young, Nancy Fraser y Drucilla Cornell, cuestionan la idea de un self desencarnado, abstracto -coincidiendo en ese punto con los comunitaristas-, del mismo modo que critican la división público-privado que legitima la invisibilización de las mujeres en las teorías de la justicia; $y$, los posmodernos, perspectiva en la que se introducen los trabajos de Michel Foucault, Jacques Derrida y Jean-François Lyotard, concurren con las críticas anteriores y, adicionalmente, reprochan la presencia de metanarrativas ilustradas en las que se muestra el ideal de un sujeto autónomo, así como las bases normativas de la política democrática en general (Benhabib, 2006a: 15). Lo novedoso de la propuesta de Benhabib es que frente a estos embates no los resuelve por la vía de una perspectiva $\mathrm{u}$ otra. Si bien considera que es necesario atender a estas críticas, está convencida de que el proyecto de la modernidad debe reconstituirse a partir de un diálogo permanente con voces que den lugar a un "nuevo universalismo". Sin duda, Benhabib defenderá el universalismo, pero en una forma que abogue por encontrar un sentido distinto. Uno, basado en la pluralidad y las diferencias de modos de ser humano. Se trata de un universalismo interactivo que ventila racionalmente las disputas normativas, acepta que la equidad y reciprocidad constituyen el principio moral y sostiene que "la diferencia es un punto de partida en la reflexión y la acción política" (Benhabib, 2006a: 176).

Derivado del diálogo que Benhabib mantiene con el comunitarismo, feminismo y posmodernismo, identificará tres cuestiones que desde su punto de vista deben ser atendidas por la teoría universalista. La primera se refiere al escepticismo hacia las pretensiones de razón legisladora, sobre las cuales se asienta el punto de vista moral en Kant; la posición original en Rawls; y, la situación ideal del habla en Habermas. La segunda es la crítica al sujeto abstracto y autónomo privilegiado por la tradición universalista (Benhabib, 
2006a). La tercera, el desenmascaramiento de la incapacidad de la razón universalista legislativa respecto a manejarse con la indeterminación y multiplicidad de contextos y situaciones vitales con las que siempre se confronta la razón práctica. En esta lógica, la distinción habermasiana entre los discursos normativos y estético-expresivos deviene en la expresión paradójica entre la justicia y la buena vida. Al final, dirá Benhabib, Habermas está más preocupado por preservar la pureza de la esfera público-normativa, identificada con la comunidad de legalidad y derechos que con la esfera privada en la que se recogería la comunidad de necesidades y solidaridad (Benhabib, 2006a: 15).

La reformulación del universalismo benhabibiano surge, precisamente, en el intersticio en el que se manifiesta esta ceguera de la teoría moral que ignora las transformaciones de la esfera privada y las repercusiones que ésta introduce a la esfera pública. El espacio en el que se cuestionan las reglas que rigen la esfera privada al quedar fuera del alcance de los derechos y la justicia. Mediante el desarrollo de una breve genealogía de las teorías del contrato social, Benhabib examina la distinción entre justicia y vida buena, que encuentra divididas, de igual manera, en el ámbito público y doméstico expresadas en la separación normativa y utópica. En su análisis aporta elementos para comprender a qué se refiere el ideal implícito de autonomía valorado por el universalismo tradicional al que se encuentran adosadas las pretensiones de razón legisladora y sujeto abstracto (Benhabib, 2006a: 179-182). En sus atisbos, la filosofía moral y política es influida por la metáfora del "estado natural". En ocasiones se dice que es un hecho, y en otras, ficción. El estado natural se describe como pesadilla (Hobbes, 1994) o como utopía (Rousseau, 2002). Kant (1976) refutará las elucubraciones de sus predecesores y transforma el estado natural de un hecho empírico a un estado trascendental. El contenido cambiante de la metáfora es menos significativo que el mensaje que encierra -apunta Benhabib-, la importancia está en la visión del ser autónomo que ofrece: se trata de un ser narcisista que ve el mundo hecho a su propia imagen y semejanza; sin conciencia ni limites de sus propios deseos y pasiones, e incapaz de verse a través de los ojos de los otros (Benhabib, 2006a: 180).

El resultado de la imposición de este dispositivo imaginario nos condujo a heredar muchos prejuicios filosóficos. Rawls (2004) y
Kohlberg (1981) consideran que el ser autónomo es desencarnado y desarraigado; la imparcialidad moral aprende a reconocer las exigencias del otro, toda vez que lo prefiguran igual a uno mismo; la equidad es la justicia pública y están convencidos de que un sistema público de derechos y deberes es la mejor manera de arbitrar conflictos, distribuir premios y legitimar exigencias (Benhabib, 2006a: 181). El problema es que en este mundo constituido a imagen y semejanza del ego masculino, la experiencia de todos aquellos sujetos que no caben en su descripción, quedan relegados a un sin-lugar en su exigencia de los derechos humanos. Su mundo está constituido a partir de una serie de negaciones. Cuando pensamos en la identidad de los diferentes se articula en torno a la falta y, por lo tanto, a la falta de autonomía. La constitución misma del discurso generó prejuicios de la teoría moral en la que el "otro" no tuvo lugar. La esfera pública y de la justicia es desplazada a la historicidad, mientras que la esfera privada, vinculada al cuidado y la intimidad, relegada a lo invariable e intemporal. En este proceso, el ego masculino transita del estado natural a la cultura, del conflicto al consenso. Entretanto, "los otros" continúan habitando un universo intemporal, condenados simplemente a repetir ciclos de la vida (Benhabib, 2006a: 181182).

La división entre la esfera pública de la justicia en la que se hace historia y el ámbito atemporal de lo privado en el que se produce la vida, es duplicada por la teoría moral universalista contemporánea. Sobre este escenario, Seyla Benhabib reformula el universalismo tradicional ensayando abrir alternativas para pensar el "derecho a tener derechos". Si la crítica comunitarista, feminista y posmoderna estuvo dirigida a cuestionar el escepticismo con respecto a las afirmaciones de una razón legislativa sobre la que se sostienen los argumentos del "punto de vista moral", la "posición original" y de la "situación del habla ideal"; a objetivar el ideal del sujeto abstracto y desarraigado del ego masculino autónomo; y, a desenmascarar la incapacidad de la razón universalista legislativa para manejarse en la multiplicidad de contextos y situaciones vitales, el universalismo interactivo elude lo meramente legislativo, tematiza el género y es sensible al contexto (Benhabib, 2006a: 16).

De esta manera, el universalismo interactivo planteado por Benhabib, propone la reformulación pragmática universal de sus bases de validez. Se 
trata de poner en relación la norma (comunidad de legalidad y derecho) y la utopía (comunidad de necesidades y solidaridad), no de construir un nuevo fundamento. En este sentido, el debate no atraviesa por la discusión de fundacionismos ni antifundacionismos, sino de reconducirlo hacia un espacio en el que el protagonista sea un self encarnado e incrustado en relaciones humanas, cuya identidad se constituya narrativamente, y en la reformulación de un punto de vista moral que dé lugar a la realización contingente de una forma interactiva entre la norma y la utopía. Es, precisamente, en esta experiencia en la que se perfila un escenario para los derechos humanos arropados por la libertad de acción política colectiva, cuya exigencia de quienes tienen necesidades y configuran su interés en torno a la solidaridad, inciden en la esfera pública de la justicia.

\section{Los derechos humanos puestos en marcha por el activismo contemporáneo}

El fin de la filosofía del sujeto ${ }^{1}$ y la crítica a la razón instrumental modificaron el significado de la utopía en nuestras sociedades (Benhabib, 2011: 188). Los movimientos sociales contemporáneos desde los movimientos de mujeres en las últimas décadas hasta los ecologistas; desde los migrantes "sin papeles" y refugiados hasta los activistas del Foro Social Mundial; desde los indígenas en su búsqueda por el reconocimiento a la autonomía como pueblos originarios hasta la lucha contra la discriminación y la homofobia, y a favor de la equiparación y reconocimiento de derechos de las personas lesbianas, gays, bisexuales, transgéneros y transexuales- reconocen que existe un "daño común" perpetrado por la arbitrariedad del ejercicio del poder que impide el desarrollo y realización de sus derechos humanos, pero no defienden la idea de que sus demandas particulares representen la universalidad de todos los grupos. Asumen sus diferencias y están conscientes de que sus experiencias están situadas de forma distinta. El reconocimiento de esta heterología de la pluralidad es concebido como un momento de fuerza -no de debilidad- para encausar su lucha por el reconocimiento de sus derechos. Estos movimientos salvaguardan el espíritu del derecho natural y la utopía social en la medida en que apuntan a crear una política de derechos, y ser titulares de tales derechos, al mismo tiempo que edifican una comunidad de necesidades y solidaridad. Recuperan el principio del derecho natural, en el sentido que Bloch propone, basado en una voluntad racional liberada, que postula una justicia que debe ser conquistada en la lucha; no una justicia desde lo alto que, distributiva o redistributivamente, prescribe una ración, sino una justicia activa, una justicia desde abajo (Bloch, 2011: 49).

Mediante el contraste y la complementariedad entre las perspectivas del "otro generalizado" y el "otro concreto", el universalismo interactivo de Benhabib visibiliza la manera en que los movimientos sociales contemporáneos intervienen en una comunidad sostenida sobre un aparato legal, político y administrativo a partir de la asociación de personas reunidas alrededor de necesidades y solidaridad, donde la acción es dirigida por un conjunto de valores e ideales compartidos que sostienen la concreción del otro sobre la base de reconocer su dignidad como un otro generalizado. La particularidad de las comunidades de necesidad y solidaridad radica en que su emergencia responde a las luchas llevadas a cabo frente a la opresión, explotación y humillación; son creadas en los intersticios de las sociedades por aquellos movimientos sociales contemporáneos que luchan, tanto por ampliar las promesas universales del espíritu objetivo -justicia, derechos sociales y políticos- como por concertar la lógica de la justicia con la amistad y la solidaridad. En esta trayectoria, la perspectiva del "otro generalizado" representa la legalidad de los derechos naturales, mientras que la del "otro concreto" refiere a la aspiración de las utopías sociales (Benhabib, 2011: 189).

Pero, cómo hacer compatibles la comunidad de legalidad y derechos (norma-otro generalizado) y la comunidad de necesidades y solidaridad (utopíaotro concreto) en la experiencia empírica desarrollada por los movimientos sociales contemporáneos, con

${ }^{1}$ Benjamín Arditi argumenta que el pensamiento basado en un fundamento ha denominado el pensamiento occidental. Esta lógica está asociada al modelo topográfico de la verdad de Platón y con la búsqueda de la certeza absoluta en Descartes. Postula que detrás de la diversidad empírica del mundo existe un orden subyacente y que ese orden es cognoscible y sirve para descifrar el significado de la diversidad de fenómenos. El cuestionamiento a esta tradición dio lugar a la creación en el terreno discursivo del post-fundamento (Arditi, 1991: 103-124). Este giro es el que permite imaginar conceptos tales como el de utopía, cuyo contenido se avizoraba en términos de imposibilidad (no realización), toda vez que remitía a teorías que habían "fracasado" en los postulados propuestos por sus autores (Marx, por ejemplo). En este apartado retomaré la noción de utopía propuesta de Bloch, para incorporarla como elemento central en torno al que se configura la acción política colectiva en los movimientos sociales contemporáneos que luchan por la defensa y realización de los derechos humanos, desde la actividad de anticipar-haciendo y trascender de esta manera lo dado en el momento (Bloch, 1977: 147). 
miras a incidir en la realización y actualización de los derechos humanos en el presente.

En la actualidad, la defensa por los derechos humanos se encuentra enmarcada por diversas normas cosmopolitas derivadas de la Declaración Universal de los Derechos Humanos de 1948, que rebasan los principios sobre los que se apoyaba la soberanía westfaliana. El trato que el Estadonación otorgaba a los ciudadanos y no-ciudadanos dejó de ser una prerrogativa libre, ahora está sujeto a una ética discursiva trasminada por los derechos universales en la que "solo son válidas aquellas normas y arreglos institucionales normativos que pueden ser acordados por todos los interesados bajo situaciones especiales de argumentación llamados discursos" (Benhabib, 2006b). E1 desafio que enfrentan los movimientos sociales contemporáneos en el proceso de la defensa de los derechos humanos, en el contexto de las normas cosmopolitas, consiste en mantener el diálogo entre norma y utopía. La interacción dinámica entre ley y política, como señala Robert Post, visibiliza el vinculo que existe entre la legalidad y la demanda -y puesta en cuestión- de las formas tradicionales del ejercicio de la justicia.

La política y la ley constituyen dos formas distintas de gestión para resolver el acuerdo o desacuerdo de los hechos sociales inevitables. Como prácticas sociales, la política y la ley son independientes e interdependientes. Son independientes, en el sentido de que son incompatibles. Someter una controversia política a una resolución legal implica sacarla del dominio político, del mismo modo que someter una controversia legal a una resolución política implica debilitar la ley. Sin embargo, política y ley son interdependientes, en el sentido de que la ley requiere de la política para producir normas compartidas que impone la ley, mientras que la política exige de la ley para estabilizar y consolidar los valores comunes de la política que se esfuerza por alcanzar. (Post, 2010: 1343)

Una de las tareas del activismo de derechos humanos radica, fundamentalmente, en lograr el acceso a la justicia; en otras palabras, cuestiona las formas tradicionales de ejercicio de la justicia a partir de la demanda política de derechos en ámbitos que rebasan el enmarcamiento estatal.
Sus prácticas involucran formas de reconocimiento que no se limitan a la participación de quienes se hallan dentro del universo de los que "cuentan" en el registro de una comunidad humana organizada, sino que es resultado del punto de intersección entre el enmarque moral y la participación democrática. La discusión sobre la aplicación de la justicia se desenvuelve a través de un ejercicio normativo, en el que las instituciones jurídicas son atravesadas por narrativas y prescripciones sociales que le otorgan sentido y legitimidad (Cover, 1983/84: 1). Un ejemplo importante en este sentido, lo constituye la lucha por los derechos humanos reemprendida durante los años sesenta del siglo pasado, cuyo marco político, jurídico y conceptual, visibiliza el planteamiento de reclamos políticos en la búsqueda de la justicia ${ }^{2}$. Y, precisamente, el principio mediante el que los actores de la sociedad civil y organizaciones internacionales activan la relación entre política y ley se desenvuelve a través del desarrollo mutuo de la solidaridad ${ }^{3}$.

Se trata de una solidaridad basada en el interés, generada comunicativamente, que toma fuerza efectiva de un relato histórico de injusticia, distinto en cada caso, pero relacionado a un sistema global (Fraser, 2008: 263).

Esta forma de solidaridad abre un espacio desterritorializado de acogida a grupos dispares, pero, en otros aspectos los enfrenta, toda vez que el desarrollo de su discurso de respeto moral y reciprocidad igualitaria depende menos de la unidad y del consenso que de las específicas diferencias entre la gente. Su fuerza radica en la combinación de diferentes apoyos: una renuncia al sectarismo etnocultural y reconocimiento a la pluralidad cultural; un contexto y un ejercicio de comunicación política compartidos (foros, muchas veces virtuales); un modelo de organización flexible que evita el temor de sus componentes a una homogenización coercitiva; y, un horizonte interpretativo global que brinda a los participantes situar sus luchas dentro del marco del capitalismo neoliberal globalizador, así como postular un enemigo común (Fraser, 2008: 263-266). Estas prácticas son puestas en marcha a través de un

${ }^{2}$ Margaret L. Satterthwaite y Deena R. Hurwitz, coordinadoras del libro Human rights advocacy stories, proponen una selección de historias con resultados positivos sobre la defensa de los derechos humanos entre los que se destacan: amnistía Internacional y sus esfuerzos por dar forma a la Convención de la ONU contra la tortura; la Campaña de Acción Pro Tratamiento VIH/AIDS (TAC, por sus cifras en inglés) en Sudáfrica; la lucha por la legalización de las identidades sexuales: el caso de Dudgeon y Toonen; el reconocimiento legal indígena sobre los derechos de la tierra: el caso de Awas Tingni en Nicaragua; la Ley de la República vs la Ley de los hermanos, sobre la prohibición francesa de los símbolos religiosos en la Escuela Pública; el caso de Akayesu, antes del Tribunal Criminal Internacional, acerca el genocidio en Ruanda; las paradojas de la construcción del Estado y los Derechos Humanos, el caso de Kabul en Afganistán (Hurwitz y Stterthwaite, Eds., 2010).

${ }^{3}$ La perspectiva de la solidaridad que observan estos grupos está relacionada con el enfoque puesto en marcha en el Foro Social Mundial, analizada por Nancy Fraser en Escalas de la justicia (2018) 
ejercicio permanente de iteraciones democráticas en el que se configuran formas de empoderamiento y lucha política.

\begin{abstract}
Mediante el uso del concepto de iteraciones democráticas' -señala Benhabib- indico formas de empoderamiento y lucha política por medio de las cuales las personas se apoderan de la promesa universalista de normas cosmopolitas, con el objetivo de imponer a las formas del poder económico y político, que buscan escapar al control democrático, la responsabilidad de rendir cuentas y la necesidad de la transparencia. El entrelazamiento de la iteración democrática con la sociedad civil global y la creación de formas de solidaridad a través de las fronteras, incluyendo el derecho universal de hospitalidad que reconoce al otro como posible conciudadano, anticipa un cosmopolitismo diferente; un cosmopolitismo por venir. (Benhabib, 2006b: 167)
\end{abstract}

La "iteración", en primer término, remitiría a una simple repetición. Sin embargo, al profundizar en la noción, es posible darse cuenta de que constituye algo más que eso, se trata de un complejo proceso de apropiación y, simultáneamente, de transformación. Es un proceso cultural e intelectual en el que pareciera que sólo ejecutamos una acción de repetición del "original", pero no es así, cuando lo llevamos a cabo, estamos creando y actualizando ese algo que considerábamos ya dado. Estos procesos de iteración son particularmente visibles en dominios tales como la interpretación legal o política, debido a la herencia de la democracia liberal sustentada en una tradición constitucional en la que la existencia del agente transcurre a través de la eterna reinterpretación, reapropiación y la reiteración del pasado. Es decir, la capacidad para recuperar la tradición en torno a la que se constituye la vida sociocultural y política de las personas está estrechamente vinculada a su capacidad de apropiarse del pasado a partir de la lectura presente (Benhabib, 2004). La capacidad para narrar el pasado es una condición fundamental en el ser humano. Cuando se pierde la cualidad para trasmitir las tradiciones, para describir la vida en colectivo, para analizar las relaciones de poder que nos anteceden; la cultura deja de ser un legado vivo, la ley deviene en un simple instrumento de dominación y un método de coerción (como la concebian Thomas Hobbes y Michel Foucault); y, la democracia deviene en un dispositivo que legaliza "por turno" el borramiento del otro.
Abordar el concepto de "iteraciones tnorma y utopía, ley y política, que desborda el patrón tradicional de los derechos humanos para repensarlo a la luz de las formas de solidaridad construidas por los movimientos sociales contemporáneos, implica rastrear esos momentos de apropiación y emergencia de lo nuevo, cuando pareciera que aún permanece anclado a lo viejo. Desde esta perspectiva, los activistas globales de derechos humanos muestran que el compromiso con normas constitucionales e internacionales que trascienden el contexto local pueden ser mediadas por las mayorías democráticas $\mathrm{y}$, en este trayecto, aparecen no sólo como sujetos, sino también como autores de sus leyes. De este modo, las iteraciones democráticas, intervienen en la política jurisgenerativa, señalada por Robert Cover (1983), a través de la cual "el demos enfrenta la disyunción entre el contenido universalista de sus compromisos constitucionales y las paradojas del cierre democrático" (Benhabib, 2004: 25). Si bien es cierto, como señalan muchos detractores de esta perspectiva (Nagel, 2005; Skinner, 2008; Walzer, 1983), que nunca ha existido una superposición perfecta entre el círculo de quienes están bajo la autoridad de la ley y los miembros plenos del demos, la ley adquiere sentido en tanto que es interpretada dentro de un contexto de significaciones que escapan a su propio control. Las leyes pueden "seguirse" porque son interpretadas, pero, es necesario decirlo, hay normas a las que escapa el control sobre las múltiples interpretaciones. Esta es la naturaleza de las reglas en general y, de la ley, en particular. El horizonte de su interpretación trasciende la fijación del significado (Benhabib, 2010: 4). En este sentido, la ley estructura una normativa universal extralegal para desarrollar nuevos vocabularios dirigidos a la población que lo demanda. Y, en esto consiste la intervención de los activistas, cada vez que colocan su exigencia a la dignidad y el respeto por los derechos humanos en el espacio público, iteran el significado y realización de tales derechos, ponen en crisis la fijación de significado de la ley, modifican la estructura del vocabulario en un contexto local y global y, abren un espacio esperanzador a nuevas formas de subjetivación política que se interponen a las relaciones existentes de poder, anticipando una justicia por venir (Benhabib, 2010: 4).

En este sentido, un ejemplo relevante lo constituye el movimiento indígena actual, impulsado en el ámbito global, cuya demanda 
gira en torno a las experiencias autonómicas y en la construcción de "lo común". ${ }^{4}$ A finales del siglo $\mathrm{XX}$, creció de manera significativa el protagonismo político de los pueblos originarios, convirtiéndose en un sujeto social y político independiente en el ámbito latinoamericano, haciendo de la lucha por la libre determinación y la autonomía el centro de su movilización. Lejos de presentar una tendencia nostálgica al ensimismamiento esencialista e identitario, su activismo apunta a la creación de espacios de convivencia y formas organizativas alternativas a las hegemónicas, desbordando tanto la lógica de lo público-estatal como la de lo privado-mercantil. Asume que su fuerza radica en su capacidad para solidarizarse con otros sujetos, quienes también han sido despojados de sus derechos -jóvenes, mujeres, migrantes, entre otros-, víctimas de los procesos de acumulación y transformación que trasminan a las instituciones estatales en el contexto global-neoliberal.

La especificidad de este proceso, leído en clave de iteraciones democráticas, radica en la creación de alianzas que rebasan el ámbito comunitario e indígena -colocándose tanto en el ámbito nacional e internacional y en relación con sujetos sociales y políticos distintos-, para llevar a cabo la exigencia del cumplimiento de los derechos humanos, apoyados en la legitimidad de sus demandas y la existencia de normas cosmopolitas. Esta lucha, enmarcada particularmente con el levantamiento del Ejército Zapatista de Liberación Nacional (EZLN) en Chiapas, México, se caracteriza por construir puentes entre diferentes sujetos con quienes comparte el "daño" de la exclusión en algún registro, y en la apuesta por abrir un espacio público cobijado por la justicia trasnacional. Inicialmente, entre comunidades y etnias distintas, hasta convertirse en un movimiento panindigenista continental, rompiendo así con su aislamiento de la comunidad tradicional-corporativa;y, más tarde, con organizaciones y grupos pertenecientes a la realidad no indígena nacional e internacional. Expresiones de lo anterior, es el esfuerzo de los zapatistas de crear redes nacionales y globales de resistencia a las prácticas del Estado neoliberal; los vínculos entre la población de Cherán, Atenco, Wirikuta y Xochicuatla, para defenderse frente al embate de la inseguridad y el desplazamiento; su relación con los migrantes para protegerse de la expulsión de los países de arribo, entre muchos otros. En el origen de este movimiento indígena independiente, se perfila la edificación de un "nosotros" que rebasa la dimensión local, étnica y nacional, y erige alianzas con otras luchas y resistencias que enfrentan al sistema hegemónico. Alianzas y cadenas de solidaridad que adquieren importancia cuando se trata de resistir a los proyectos que los despojan de sus derechos humanos, rompiendo con el asilamiento en que a menudo se encuentran los excluidos, visibilizando y dando voz a las víctimas surgidas en diferentes contextos y prácticas. Estos esfuerzos de articulación de sujetos distintos crean un espacio global de oposición a las políticas neoliberales mediante una suerte de globalización de las resistencias, a través del ejercicio de iteraciones democráticas que ponen al descubierto, una vez y cada vez, múltiples y diversas formas de la injusticia.

Lo que sigue de esto, es una nueva apreciación de los activistas -o movimientos emancipatorios contemporáneos de derechos humanos, para tomar un término de Nancy Fraserconstituidos alrededor de un daño que los impele a enfrentar desde un conjunto de apoyos solidarios la cuestión de la injusticia. La fuente de estos grupos para incidir en la agenda pública tiene su fortaleza en su capacidad para la acción política, toda vez que son capaces de plantear reclamos y marcos de negociación dirigidos a la búsqueda de la justicia que podrán ser interpretados en términos de realización de la utopía social. Esto significa que identifican el problema social a partir de la configuración de argumentos autónomos, lo que les permite visibilizar el daño; legitiman el problema mediante prácticas de solidaridad basadas en el interés y las necesidades compartidas, donde su potencia efectiva deriva de un relato histórico de injusticia; movilizan la acción política con respecto al problema, e impulsan demandas por la reivindicación de la justicia mediante procesos de iteración democrática, cuyo ejercicio pone en marcha una política jusgenerativa; configuran la formación de un plan institucional de acción para enfrentar el problema en el que el surgimiento y la extensión del régimen de derechos humanos que, pese a todas sus hipocresías a escala mundial (Benhabib, 2004: 127), da lugar a nuevas formas de pertenencia desterritorializada, al debilitar

${ }^{4}$ Este ejemplo lo retomo del espléndido trabajo de investigación "Autonomía indígena y re-construcción de lo común en clave de apertura de la ciudadanía", realizado por Andrea Spotti (2019). 
la línea que separa los derechos humanos de los derechos ciudadanos y, finalmente, transforman el plan oficial de la implementación empírica a través de la desagregación de los derechos humanos que afirma e inscribe un nuevo sentido de la justicia global, aún no resuelto, pero puesto en marcha con la solidaridad de personas en el mundo que buscan resolver sus necesidades para alcanzar una vida digna.

\section{Transfiguración de los derechos humanos en el marco del "otro generalizado" y el "otro concreto"}

Seyla Benhabib describe dos concepciones de relación ser-otro en las que se configuran tanto las perspectivas morales que identifica con el "otro generalizado" como las estructuras de interacción expresadas en el "otro concreto". En la teoría moral contemporánea, estas concepciones son irreconciliables, antagónicas. La distinción refleja las paradojas encarnadas en la teoría moral y política de los primeros tiempos de la modernidad entre autonomía, crianza, independencia y vínculo; público y privado; y, más ampliamente, entre justicia y vida buena. El punto de vista del otro generalizado -como afirma Benhabib- exige reconocer a cada individuo como ser racional sujeto a derechos y deberes del mismo modo que quisiéramos vernos a nosotros mismos. Este punto de vista demanda abstraernos de la individualidad e identidad concreta del otro. $\mathrm{Su}$ dignidad moral no radica en el reconocimiento de las singularidades, lo que le es común es su capacidad para comportarse como un agente racional. Las normas de igualdad y reciprocidad formal son las que gobiernan este tipo de relación, cuya interacción es pública e institucional, adscrita a la comunidad de legalidad y derechos (Benhabib, 2006a: 182-183). Sin embargo, si partimos de la idea de que esta comunidad incluye a los "iguales", el contrato social camuflado reposa sobre la exclusión de quienes no pertenecen a dicha comunidad -cuestión que ya Arendt vislumbraba cuando se refería a las personas "sin-Estado", cuya condición las excluía no solo de los derechos ciudadanos, sino de sus derechos humanos y de su misma humanidad, de alli su radical interés en reconfigurar el principio del "derecho a tener derechos” (Arendt, 1949; 1968; 1998)-, reeditando un nuevo fundamento de poder excluyente. La esfera pública imaginada por Hobbes (1994) o
Locke (2004), estaría constituida por el jefe de familia y los propietarios sobre los que se fundaría la comunidad política, lo que deja afuera a las mujeres, niños, trabajadores asalariados y pobres (no propietarios), quienes constituyen la esfera de la necesidad (o privada). Vale recordar el modelo griego antiguo de democracia en el que la esfera privada era concebida en términos de necesidad, y la pública como el de libertad, tal y como lo afirma Arendt (1968).

En este sentido, la idea del otro generalizado incluye, pero a la vez excluye. Este vínculo hace florecer la libertad de los iguales, de acceder a los mismos derechos, configurado en la expresión de una "hermosa familia"; pasa de ser inofensiva a perturbadora, reclama la igualdad de hecho, no de derecho (Agra Romero, 1994: 153). La mirada del otro generalizado constituye el punto de vista moral, normativo, por excelencia. Lo que marca esta lógica unidireccional es que todos y cada uno debemos ser considerados seres racionales, con los mismos derechos y deberes, haciendo abstracción de la individualidad concreta del otro. Se trata de una comunidad de "iguales" que encuentra su origen en la metáfora de la familia inscrita en el entusiasmo patriótico acuerpado en la Declaración de los derechos del hombre y del ciudadano, gestada en la Revolución francesa (David, 1987: 8), idea sobre la que se configura la lista irrealizable de los derechos humanos que compete a la visible "pérdida de realidad", derivada de la imposibilidad de llevar a cabo un deber al que no puede corresponder por su incapacidad de acción (Menke, 2007: 741; Arendt, 1948). Sobre esta afirmación, Arendt configura la interconexión del (derecho)-a-(tener derechos). La primera parte de esta frase, como indica Benhabib, remite a un imperativo moral, se trata de un derecho la membresía. Esta primera estructura del derecho, dirigida a la identidad del (los) otro(s) a quien(es) se reclama el reconocimiento como una persona derechohabiente, queda abierta e indeterminada, no depende de la condición de ser ciudadano o no, sino del derecho al reconocimiento por el simple hecho de ser un "ser humano" (Benhabib, 2004: 56). En este sentido, la humanidad misma se convertiría en la destinataria de este reconocimiento; sin embargo, como afirma Arendt, no existe ninguna certeza de que esto se lleve a cabo (Arendt, 1968: 298). De este modo, la condición de persona es contingente a su reconocimiento en la membresía, lo que introduce la noción de la segunda frase de 
la estructura discursiva tener derechos (Benhabib, 2004: 57), cuya acción resulta del previo derecho a la membresía, lo cual significa el derecho (y sus respectivos deberes) a vivir como miembro de una comunidad humana organizada en la que se es juzgado por sus acciones y opiniones. Esta doble adscripción del "derecho a tener derechos", rompe las formas a priori de la pertenencia a una comunidad humana organizada, basada en la egología trascendental kantiana donde se reúnen, merced a la prodigiosa decisión, los derechos humanos a la ciudadanía, dejando sin protección a individuos y pueblos frente a las arbitrariedades de la soberanía del Estado. Por un lado, postula una comunidad jurídico-civil de co-socios que estén en relación con el deber de responsabilidad recíproca; $\mathrm{y}$, por otro, el deber de reconocerse como miembros, como individuos protegidos por las autoridades político-legales, a quienes deben ser tratados como personas habilitadas para disfrutar de derechos (Benhabib, 2004: 57-58). El vínculo entre estos dos tipos de derecho es el que los movimientos sociales contemporáneos ponen en marcha mediante la experiencia de la acción política global, encarnada en la comunidad de necesidad y solidaridad.

Cada vez que los activistas globales demandan la exigencia de justicia y realización de los derechos humanos, mediante el ejercicio de iteraciones democráticas, colocan en el centro del debate la importancia de la distinción entre la legalidad y los derechos, y una ética del cuidado y la responsabilidad -norma vs utopía social; comunidad de legalidad y derechos vs comunidad de necesidad y solidaridad; otro generalizado vs otro concreto-. Visibilizan el modo en que la postura racionalista anula al otro concreto, la manera en que se impone la singularidad de la conciencia "de los iguales" que pretende ser inmediatamente universal. En la Fenomenología del espíritu, Hegel ya vislumbraba los peligros de una comunidad fundada sobre la "ley del corazón y el desvarío de la infatuación" (Hegel, 1985: 217 y ss.). Seguir la ley del corazón, sus palpitaciones resonando por el "bien de la humanidad", se truecan en la furia de la infatuación demencial: "Enuncia el orden universal como una inversión de la ley del corazón y su dicha, manejada por sacerdotes fanáticos y orgiásticos déspotas y sus servidores, quienes humillando y oprimiendo, tratan de resarcirse de su propia humillación" (Hegel, 1985: 222). En este proceso de exaltación de los iguales y en su afán de construir una comunidad de justicia proclaman la individualidad del orden vigente; pero de un modo inmediato, la realidad, precisamente la ley como orden vigente, deviene en nulidad. La forma de unidad que había alcanzado no es más que una realidad enajenada. En efecto -dirá Hegel- por ser este orden la ley de todos los corazones y por ser todos los individuos, de este modo inmediato, este universal, es dicho orden de una realidad que solo es la realidad de la individualidad que es para sí misma o del corazón. Así, lo que aparece como universal, al ser resultado de la contradicción de las leyes singulares, la lucha de todos contra todos, en la que cada cual trata de hacer valer su singularidad, pero sin lograrlo, porque experimenta la misma resistencia y porque su singularidad es disuelta por las otras y a la inversa, simplemente conducirá al terror y la guerra, al estado de hostilidad universal (Hegel, 1985: 223). En este sentido, la "ley del corazón” en lugar de convertirse en un principio constructivo que confirme y corrobore el verdadero orden ético de la comunidad de legalidad y derechos, fundada sobre el principio de los "iguales" se transfigura en un principio destructivo y subversivo.

Al poner en relación el punto de vista del "otro concreto", esta lectura adquiere una complejidad diferente. La solidaridad en torno a la que se articulan los activistas globales para la defensa de los derechos humanos apuntala otros modos de relación de comprender la moralidad; un proceso que podría llevarnos a establecer juicios morales justos. Desde esta perspectiva, lo principal es comprender que cada ser racional es un individuo con una historia, identidad y constitución afectivoemocional concreta, de donde se desprende que lo que tenemos en común es la individualidad. La relevancia de esta perspectiva radica en tratar de asumir las necesidades del otro, sus motivaciones, lo que busca y desea. En ese trayecto, las normas que gobiernan este tipo de relación son las normas de equidad y reciprocidad complementaria, justo lo que colocan en el centro los movimientos sociales contemporáneos cuando aluden al principio de solidaridad: "cada uno tiene derechos a esperar y suponer formas de conducta del otro a través de las cuales el otro se sienta reconocido y confirmado como un ser individual concreto con necesidades, aptitudes y capacidades específicas" (Benhabib, 2006c: 183) y, a la vez, cobijado por un conjunto de normas universales que le permiten concretar su dignidad humana. De esta manera, la mediación 
que Benhabib establece para pensar la norma (otro generalizado) y la utopía (otro concreto), se expresa en la doble adscripción que problematiza la frase del "derecho a tener derechos" propuesta por Arendt, mediante la que los activistas globales por la defensa de los derechos humanos ponen en marcha el vínculo entre política y ley, como un camino de reencuentro entre la comunidad de la legalidad y derechos, y la comunidad de necesidades y solidaridad, donde se conjugarían el derecho a tener derechos y el permanente cuestionamiento de los derechos humanos universales.

\section{Referencias}

Arendt, H. (1998). The Human Condition. ChicagoLondres: University of Chicago Press.

(1968). The Origins of Totalitarianism. Nueva York: Harcourt, Inc.

Arditi, B. (1991). Conceptos. Ensayos sobre teoría política, democracia y filosofía. Asunció: CDE y RP Ediciones.

Benhabib, S. (2011). Dignity in Adversity. Human Rights in Troubled Times. Cambridge: Polity Press. (2006a). El Ser y el Otro en la ética contemporánea. Feminismo, comunitarismo y posmodernismo. Barcelona: Gedisa.

(2006b). Another Cosmopolitanism. Nueva York: Oxford University Press.

(2006c). Las reivindicaciones de la cultura. Igualdad y diversidad en la era global. Buenos Aires: Katz.

(2004). The Rights of Others. Aliens. Residents and Citizens. Cambridge: Cambridge University Press.

(1986). Critique, Norm and Utopia. A Study of the Foundations of Critical Theory. Nueva York: Columbia University Press.

Bloch, E. (2011). Derecho natural y dignidad humana. Madrid: DYKINSON.

(1977). El principio de esperanza. Madrid: Aguilar.

David, M. (1987). Fraternité e Révolution Française 17891799. París: Aubier.

Fraser, N. (2008). Escalas de justicia. Barcelona: Herder. Habermas, J. (1987a). Teoría de la acción comunicativa,

I. Racionalidad de la razón funcionalista. Madrid: Taurus.

(1987b). Teoría de la Acción comunicativa,

II. Racionalidad de la acción y racionalidad social. Madrid: Taurus.

Hegel, G.W.F. (1985). Fenomenología del espíritu. México: FCE.

Hobbes, T. (1994). Leviathan. Indianapolis: Hackett Pub. Co.

Hurwitz, D. y Stterthwaite, M. (2010). Human Rights
Advocacy Stories. Nueva York: Thomson Reuters/Fundation Press.

Kant, I. (1976). Moral Philosophy. Nueva York: Garland.

Kohlberg, L. (1981). Essays on moral development. Nueva York: Harper and Row.

Locke, J. (2004). Segundo tratado sobre el gobierno civil: un ensayo acerca del verdadero origen y fin del gobierno civil. Madrid: Alianza.

Nussbaum, M. (2006). Frontiers of Justice: Disability, Nationality, Species Membership. Cambridge, MA: Harvard University Press.

Rawls, J. (1999). The Law of Peoples, en J. Rawls, Colected Papers, Samuel Freeman (ed.), Cambridge, MA: Harvard University Press.

(2004). El liberalismo politico. Barcelona: Crítica.

Rousseau, J. (2002). El contrato social o Principios de derecho politico. Madrid: Tecnos.

Skinner, Q. (2008). Liberty Beforre Liberalism, Cambridge: Cambridge University Press.

Walzer, M. (1994). Thick and Thin: Moral Argument at Home and Abroad. Notre Dame IN: University of Notre Dame.

(1983). Spheres of Justice: A Defense of Pluralism and Equality, Nueva York: Basic Books.

Hemerografía

Arendt, H. (1949). The Rights of Man: What are They? Modern Review, Vol. 3, Núm. 1, junioseptiembre, 24-36.

Buchanan, A. (2010). The Egalitarianism of Human Rights, Ethics, Vol. 120, julio, 679-710 pp.

Cover, R. M. (1983/84). Foreword: Nomos and Narrative. The Supreme Court 1982 Term, Harvard Law Review, Vol. 97, Núm. 4, enero, 4-68.

Nagel, T. (2005). The Problem of Global Justice, Philosophy and Public Affairs, Vol. 33, marzojunio, 113-144.

Menke, Ch., Kaiser, B. y Thiele, K. (2007), 'Aporias of Human Rights' and the 'One Human Rights': Regarding the Coherence of Hannah Arendt's Argument, Social Research, Vol. 74, núm. 3, septiembre-diciembre, 739-762.

Post, R. (2010). Theorizing Disagreement: Reconceiving the Relationship Between Law and Politics, California Law Review, Vol. 98, Núm. 6, agosto, 1319-1350

\section{Páginas web}

Agra Romero, M. X. (1994). Fraternidad (un concepto político a debate). Consultado: 1 de septiembre de 2018. Disponible en: http://e-spacio.uned. es/fez/eserv/bibliuned:filopoli-1994-3-1D43C2713CB1-A107-F8F4-5AAEEE8EA020/fraternidad concepto.pdf

Benhabib, S. (2010). Human Rights, Sovereignty and Democratic Iterations. Consultada: 16 de septiembre de 2018. Disponible en: http:// 
www.ourcommonfuture.de/fileadmin/user upload/ dateien/Reden/Benhabib.pdf

(2004). Seyla Benhabib Interview: Conversations with History: Institute of International Studies, UC Berkeley. Regents of the University of California. Consultada el 16 de septiembre de 2018. Disponible en: http:// globetrotter.edu/people4/Benhabib/benhabib-con3. $\underline{\mathrm{html}}$

Naussbaum, M. (1997). "Capabilities and Human Rights”, Fordham Law Review, Vol. 66, pp 273-300. Consultado: 14 de septiembre de 2018. Disponible en: http://ir.lawnet.fordham.edu/flr/ vol66/iss $2 / 2$

\section{Trabajos de tesis}

Spotti, A. (2019). Autonomías indígenas y re-construcción de lo común en clave de apertura de la ciudadanía. Tesis de Maestría en Ciencias Sociales. Ciudad de México: Universidad Autónoma de la Ciudad de México. 